\title{
Flowering Stage Drought Stress Resistance in Upland Rice in Relation to Physiological, Biochemical Traits and Yield
}

\author{
B.K. Mishra ${ }^{1 *}$ and G.S. Chaturvedi ${ }^{2}$ \\ ${ }^{1}$ Department of Plant Physiology, Institute of Agricultural Sciences, Banaras Hindu \\ University, Varanasi-221005, U. P., India \\ ${ }^{2}$ Centre of Advance Studies in Plant Physiology and Department of Crop Physiology, \\ Narendra Deva University of Agriculture and Technology, Narendra Nagar (Kumarganj), \\ Faizabad-224229, U.P., India \\ *Corresponding author
}

\section{A B S T R A C T}

Drought stress at flowering stage in upland rice is most damaging cause of yield reduction. Impact of drought stress at flowering stage on morphological, physiological and

\section{Keywords}

Upland rice, Drought stress, Flowering, Plant height, Leaf area, Chlorophyll, Root/shoot ratio, Proline, Sugar, Grain yield

Article Info

Accepted:

04 January 2018

Available Online:

10 February 2018 biochemical traits, yield and yield components are less understood. Present experiment was executed in pots under glass house conditions by taking six upland rice varieties namely Bagri, Nankawa, Bakaiya, N-22, Ashoka-228 and NDR-97. Drought stress at (80 $\mathrm{KPa} \pm 2 \mathrm{SMT}$ ) was imposed by withholding irrigation at $50 \%$ flowering stage. We observed drought stress significantly affects all investigated traits. Plants having lower plant height, higher reduction in leaf area, higher root volume and root/shoot ratio under drought was well adapted to drought. Higher leaves chlorophyll content and lesser reduction under drought, increased accumulation of soluble sugar in culm, leaf sheath and leaf blade and more reduction in starch content were linked with better drought resistance in upland rice. Higher proline content in leaves, higher biomass, higher panicle number, higher percent fertile spikelets were the traits associated with higher grain yield under drought stress. Among all studied varieties $\mathrm{N}-22$ exhibited the above desired traits at flowering stage drought resistance may be considered as drought resistant. NDR-97 and Ashoka-228 were moderately resistant, while Bagri was found most sensitive among all. It is concluded from the present experiment that $\mathrm{N}-22$ can be used as parent donor in upland rice breeding programme and the investigated traits can be used as selection criterion.

\section{Introduction}

Rice is an important constituent of staple food for more than three billion population and it is accounts for their $50 \%$ to $80 \%$ calorie needs on daily basis. Drought stress rigorously impairs rice production. Globally, around 23 million hectares of rainfed rice production is affected by drought stress (Seeraj et al., 2011). It is believed that climate change strictly affects the water resources and frequencies of drought are expected to increase in near future. Due to the climate change, in future there is possibility of incidence of more droughts; rice yield is expected to be affected more (Ray et al., 2015). Rice eco-system 
mostly suffers flowering stage drought both in upland and lowland. Upland rice is relatively more vulnerable to flowering stage drought than lowland; because it is mostly dependent on rainfall distribution and residual precipitation (Fukai and Cooper, 1995). In South Asian countries mainly in India, most of rainfall occurs between first week of July to last week of August and there is a chance of no-rain during mid-September to midNovember and this is the period which coincides the flowering stage (Chaturvedi et al., 1996; Mishra, 2005). Upland rice is grown both in plains and hills, the average yield of upland rice is very low (1.08 /ha) and highly unstable year to year.

Low moisture supply at flowering is most serious and common concern in upland rice ecosystem. Upland rice yield is highly variable because of drought especially at flowering stage. Flowering stage drought is very devastating and sometimes 70-80 per cent yield losses occur. Extensive work had already been done on vegetative stage drought resistance in rice (Yang et al., 2014) but research work on flowering stage drought in rice is limited. Therefore, there is need to identify good donors of upland rices tolerant to flowering stage drought (Chaturvedi and Ingram, 1988; Mishra, 2005). It is well documented that drought tolerance is a very complex trait, which is a joint role of a variety of morphological, physiological and biochemical traits (Mishra, 2005, Pandey and Shukla, 2015). Under drought stress, plant height, leaf area development, root volume, root/shoot ratio, chlorophyll, starch, soluble sugar and proline contents, plant biomass, panicle number, fertile spikelets and grain yield were used in many drought stress experiments to characterize the genotypic performance in rice (Mishra, 2005; Maisura et al., 2014). Hence, keeping above considerations in mind the present investigation was carried out to determine the impact of drought stress at flowering stage in upland rice varieties on physiological, biochemical traits, yield and yield components.

\section{Materials and Methods}

Experiment location, rice seeds sowing methods and imposition of drought stress

The present experiment was conducted in pots (12" $x$ 8") in the glass house facility at Narendra Deva University of Agriculture and Technology Narendra Nagar, Kumarganj, Faizabad (India) during Kharif season. Soils were collected from upland soil (oxidized soils) from Instructional Farm and it was finally mashed and mixed with fertilizer at the rate $\mathrm{N}$ : $\mathrm{P}: \mathrm{K}$ 100:40:40 $\mathrm{kg} \mathrm{ha}^{-1}$ on the soil weight basis. Exactly $10 \mathrm{~kg}$ mixed soil was filled in each pot. Healthy and bold rice seeds of six upland varieties namely Bagri; Nankawa; Bakaiya; N-22; Ashoka-288 and NDR-97 were collected from the Crop Research Centre, Masodha, Faizabad. Seeds were directly seeded in each pot under optimum soil moisture level. After 10 days of seedling emergence, three plants in each pot were finally maintained by thinning. Water deficit was created at $50 \%$ flowering by withholding irrigation in pots till the soil moisture tension (SMT) was reached upto 80 $\mathrm{KPa}+2$ (measured by soil moisture tensiometer). Approximately, 15 days withholding water was needed to maintain SMT of $80 \mathrm{KPa} \pm 2$. However, control pots were frequently irrigated to optimum field capacity level.

\section{Measurement of physiological traits}

Physiological traits were recorded after stress treatment in drought stressed and control plants in both treatments. Plant height was measured from the surface of soil to the top of the panicle with the help of meter scale. Leaf 
area was measured by automatic leaf area meter (LICOR-U.S.A. Model LI - 3000). Root/shoot ratio was determined in shoot samples and root samples collected at specific stage of sampling from control as well as drought stressed treatments, these samples were oven dried for 1 hours at $100^{\circ} \mathrm{C}$ and after that at $65^{\circ} \mathrm{C}$ till a constant weight is attained. Root/shoot ratio was determined by dividing root/shoot dry weight. Total biomass was determined adding the dry weight of all above ground part except root biomass and expressed in $(\mathrm{g})$ plant $^{-1}$. Root volume was determined by water displacement method with graduated cylindrical flask as described by (Rao et al., 1971).

\section{Biochemical traits}

\section{Extraction of chlorophyll content}

Total chlorophyll content was determined in freshly harvested first fully expanded leaf from the top. The chlorophyll extraction was done in dimethyl sulfoxide (DMSO) according to the method described by (Hiscox and Israelstam 1979). Leaves were washed thoroughly and cut into small pieces. $25 \mathrm{mg}$ of fresh leaf samples were placed in test tubes containing $5 \mathrm{~mL}$ DMSO. Test tubes were kept for $2 \mathrm{~h}$ (till leaves became pale) in hot air oven at $70{ }^{\circ} \mathrm{C}$ for chlorophyll extraction. The final volume of supernatant was made to $10 \mathrm{~mL}$ and absorbance was observed at 645 and $663 \mathrm{~nm}$ using DMSO as blank with help spectrophotometer (Elico SL 160). The chlorophyll content was estimated by the formula given by (Arnon, 1949) and expressed as $\mathrm{mg} \mathrm{g}^{-1}$ fresh weight.

\section{Soluble sugar and starch determination in different plant parts}

Soluble sugar and starch contents were determined by anthrone method (Dubois et al., 1956) in culm, leaf sheath and leaf blade. It was recorded in control and drought stressed plants, expressed as $\mathrm{mg} \mathrm{g}^{-1}$ dry weight. The absorbance was measured at $620 \mathrm{~nm}$ by a spectrophotometer (Elico SL 160). The amount of the sugar in the leaf samples was calculated by standard curve.

\section{Estimation of proline content}

Proline content was determined in first fully expanded leaf from top by the method (Bates et al., 1973).

The absorbance of toluene fraction was read at $520 \mathrm{~nm}$ with the help of spectrophotometer (Elico, SL196) against toluene blank. Concentration of proline in the plant samples was estimated by referring to a standard curve of proline.

\section{Determination of yield and yield components}

Observation for yield and yield attributes were taken on five replicate plants already tagged for this purpose. Number of panicles were counted and expressed as panicle per plant. Panicles were collected from each pot and threshed by hand to remove all filled and unfilled spikelets. The spikelets were expressed in terms of \% fertility in control and drought stressed plants.

Total grain yield (g) plant ${ }^{-1}$ was determined in five replicated pots tagged for this purpose in control as well as drought stressed plants when the moisture content of grain was $14 \%$. Grain yield was recorded on electronic balance (AGDR-200).

\section{Statistical analysis}

Data presented are mean of five independent observations with five replicates each. The data were subjected to ANOVA by SAS 9.2 software (USA). The differences at $(p \leq 0.05)$ were considered as significant. 


\section{Results and Discussion}

\section{Effect of drought stress at flowering stage on physiological traits}

Drought stress significantly decreased plant height in drought stressed plants $(\mathrm{P} \leq 0.05)$ of all varieties as compared to control plants (Fig. 1a). The minimum decrease was noticed in NDR-97(3.47\%) followed by Ashoka-228 (4.45\%), while decrease was generally more in Bakaiya $(11.35 \%)$ followed by Nankawa $(10.35 \%)$. As compare to control plants, leaf area declined significantly $(\mathrm{P} \leq 0.01)$ under drought stress (Fig. 1b). Maximum decline was recorded in $\mathrm{N}-22$ (34.05\%) followed Ashoka-228 (29.06\%), while the minimum decline in leaf area was recorded in Bagri $(16.61 \%)$. Root volume differed significantly $(\mathrm{P} \leq 0.01)$ with respect to variety, treatment and variety $\times$ treatment (Fig. 1c). Root volume was the maximum in $\mathrm{N}-22$ in both control and drought stress treatment. The minimum reduction under stress was recorded in $\mathrm{N}-22$ (9.15\%); nevertheless, reduction was the maximum in Nankawa and Bakaiya $\approx(41.00$ $\%)$. Drought stress significantly decreased root/shoot ratio $(\mathrm{P} \leq 0.01)$ in all varieties (Fig. 1d). As compared to control plants drought stress caused reductions in root/shoot ratio was minimal in N-22 (2.86\%), Ashoka-228 (4.20\%) and NDR (4.14\%). However, reduction was generally higher in Nankawa $(22.11 \%)$, Bakaiya $(15.66 \%)$ and Bagri $(6.35 \%)$ under drought stress than the control plants.

\section{Effect of drought stress at flowering stage on biochemical traits}

Significant differences in leaf chlorophyll content $\left(\mathrm{mg} \mathrm{g}^{-1} \mathrm{fw}\right)$ was recorded with respect to variety, treatment and variety $x$ treatment $(\mathrm{P}$ $\leq$ 0.01), (Fig. 2a). Chlorophyll content was higher and reduction in chlorophyll content under drought stress than the control plants was of lower magnitude in N-22 (14.08\%), followed by Ashoka-228, (23.64\%). But, reduction as compared with others was more in variety Bagri $(61.59 \%)$ followed by Bakaiya (51.34\%). Starch content in different plant parts viz. culm (Fig. 2b), leaf sheath (Fig. 2c) and leaf blade (Fig. 2d) was significantly declined in drought stressed plants than the control $(\mathrm{P} \leq 0.001)$. Drought stress induced reduction in culm starch content (Fig. 2b) was more in N-22 (65.36\%) followed by NDR-97 (52.59\%), but, the minimum was in Bagri (7.77\%) followed by Nankawa (11.86\%). Similarly, leaf sheath starch content (Fig. 2c) was also declined, the maximum reduction was in N-22 (86.06\%) followed by NDR-97 (80.14\%), however, the minimum reductions was in Bagri (11.07\%) followed by Bakaiya (12.29\%). It was evident that leaf blade starch content decreased in same way as in other plant parts on account of drought stress (Fig. 2d). Drought stress induced reductions in leaf blade was the maximum in $\mathrm{N}-22(73.39 \%)$ followed by NDR-97 (64.75\%), while it was the least in varieties viz. Nankawa and Bakaiya $\approx(40 \%)$. Soluble sugar content in culm (Fig. 2e), leaf sheath (Fig. 2f) and leaf blade (Fig. 2g) differed significantly with respect to variety, treatment and variety $x$ treatment $(\mathrm{P} \leq 0.001)$, it increased in different plant parts in drought stressed plants than the control. On account of drought stress culm soluble sugar (Fig. 2e), leaf sheath (Fig. 2f) and leaf blade (Fig. 2g) was enlarged the maximum in $\mathrm{N}-22$ (5.08, 3.07, 5.43 folds) followed by NDR-97 (2.63, 2.41, 3.11 folds), but the enlargements were generally the minimum in varieties namely in Bagri (1.21, 1.9, 1.99 folds), Bakaiya (1.96, 2.42, 2.09 folds) and Nankawa (1.48, 2.53, 2.22 folds), respectively. Drought stress significantly increased the proline content in leaves (Fig. $2 \mathrm{~h})$ of all varieties $(\mathrm{P} \leq 0.001)$. The maximum increase under drought stress as compare to control plants was in $\mathrm{N}-22$ (5.15 folds) followed by NDR-97 (3.24 folds), 
nevertheless, increment was the minimum in Bagri (1.99 folds) followed by Bakaiya (2.10 folds).

\section{Effect of drought stress at flowering stage yield and yield attributes}

Biomass plant ${ }^{-1}$ (Fig. 3a) decreased significantly under drought stress in all varieties than the control $(\mathrm{P} \leq 0.001)$. Variety $\mathrm{N}-22$ registered the highest biomass under drought and control treatments with a minimum reduction of $(23.46 \%)$ on account of drought over control. On the other hand, varieties namely Bagri (63.43\%) followed Nankawa (56.30\%) have registered the higher reduction under drought stress than the control plants. Moreover, imposition of drought stress at flowering stage had significant negative impact on panicle number plant ${ }^{-1}$ in drought stressed plants (Fig. 3b) as compare to control $(\mathrm{P} \leq 0.001)$. In all studied varieties $\mathrm{N}-22$ followed by NDR-97 and Ashoka-228 were evaluated for having more panicle number in drought stress as well as control conditions.

While, Bagri followed by Nankawa was noticed lower panicle number plant ${ }^{-1}$ within the drought stressed as well as control conditions. Nevertheless, drought stress imposed at flowering stage significantly declined fertile spikelets \% (Fig. 3c) in drought stressed plants in all genotypes than the control $(\mathrm{P} \leq 0.001)$. Under control and drought stress conditions fertile spikelets $\%$ were more N-22 and then NDR-97 and Ashoka-228. Nevertheless, fertile spikelets percentage was generally lower and at par in Bagri, Nankawa and Bakaiya. In addition grain yield plant ${ }^{-1}$ (Fig. 3d) decreased significantly on account of drought stress when it was imposed at flowering stage in all varieties than the control plants $(\mathrm{P} \leq 0.01)$. Among all varieties $\mathrm{N}-22$ exhibited the maximum grain yield and minimum reduction in yield i.e., only $26.67 \%$ over control was found under drought stress condition. However, reductions under drought stress over control in varieties namely NDR-97 and Ashoka-228 was $\approx 42 \%$, nevertheless, the maximum reduction was in Bagri $(72.00 \%)$.

Drought stress is a vital and most damaging abiotic stress; it is accountable for the rice yield loss globally. Drought stress caused several possessions on rice crop when exposed to drought stress at any particular stage or throughout the growing period. Such possessions affects the crops various morphological, physiological, biochemical traits and finally yield and yield components. Similarly, the genotypic/varietal variability and differences in above mentioned traits are well documented for characterizing drought resistance in rice or other cereals (Mishra 2005, Hasanuzzaman et al., 2014).

In the present experiment decreased plant height in all rice varieties in drought stressed plants was evident and well documented that when water stress developed plants seldom respond to stress by slowing down their shoot growth; this is a very common morph physiological adaptation to water stress and such processes acts as a survival practice (Zhu 2002, Mishra 2005). Reduction in plant height during drought probably due to reduction in turgor pressure, cell growth is rigorously spoiled. Drought stress is known to influence cell elongation and expansion as well as hamper cell enlargement other than the cell divisions (Shao et al., 2008, Jaleel et al., 2009) as result the plant height was decreased (Mishra 2005, Pandey and Shukla 2015).

Leaf area per plant declined by drought stress. Reduction in leaf area is might be due to sharp reduction in process of cell division and leaf elongation on account of drought stress as reported by others in rice (Pandey and Shukla 2015, Jaleel et al., 2009, Mishra 2005). The other possible reason of higher reductions in 
leaf area in varieties viz. N-22 and Ashoka228 was mainly due to higher degree of leaf rolling plasticity under drought, is a character associated with drought resistance, nevertheless, lower reduction in leaf area as in case of variety Bagri is regarded its poorer performance under drought although leaf rolling scoring was not taken in account in the present experiment but it is also a reason as mentioned in rice (Pandey and Shukla 2015). Reduced leaf area is believed to be advantageous, it leads to reduced light interception, transpiration, reduced dehydration and it may also help in maintaining internal plant water status (Feng et al., 2012).

Fig.1 Impact of flowering stage drought on; (a) plant height (cm); (b) leaf area $\left(\mathrm{cm}^{2} / \mathrm{plant}\right) ;$ (c) root volume (cc); (d) root shoot ratio, in six upland rice varieties
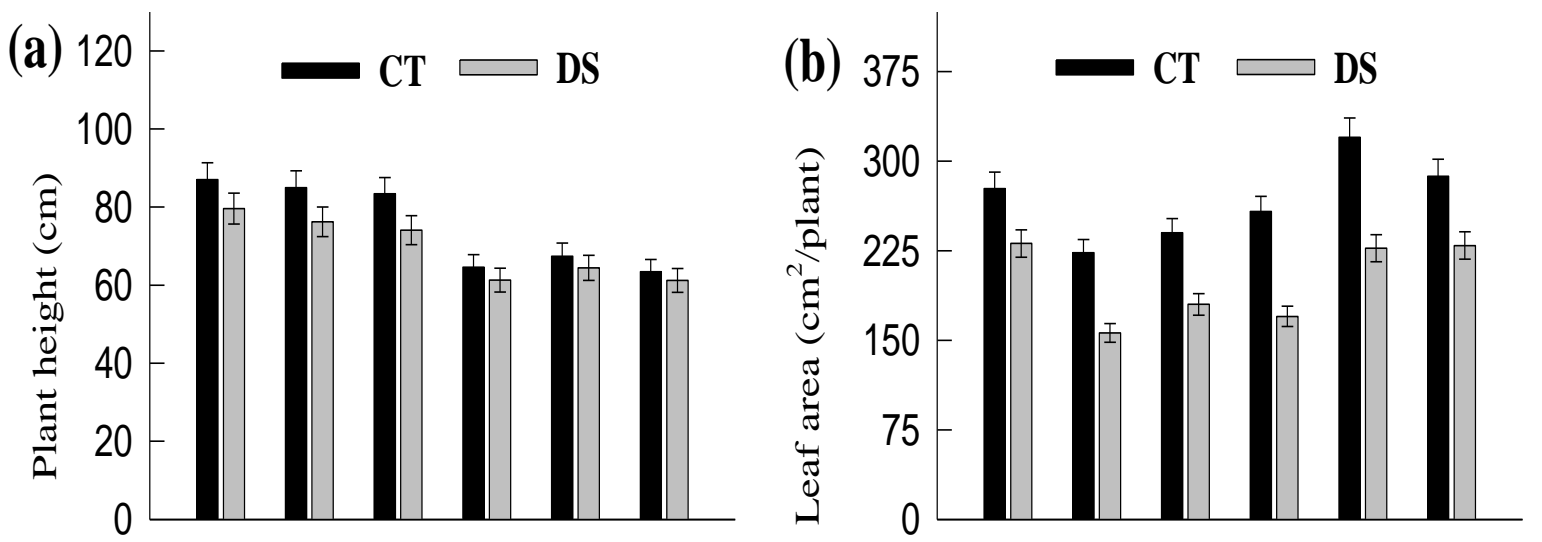

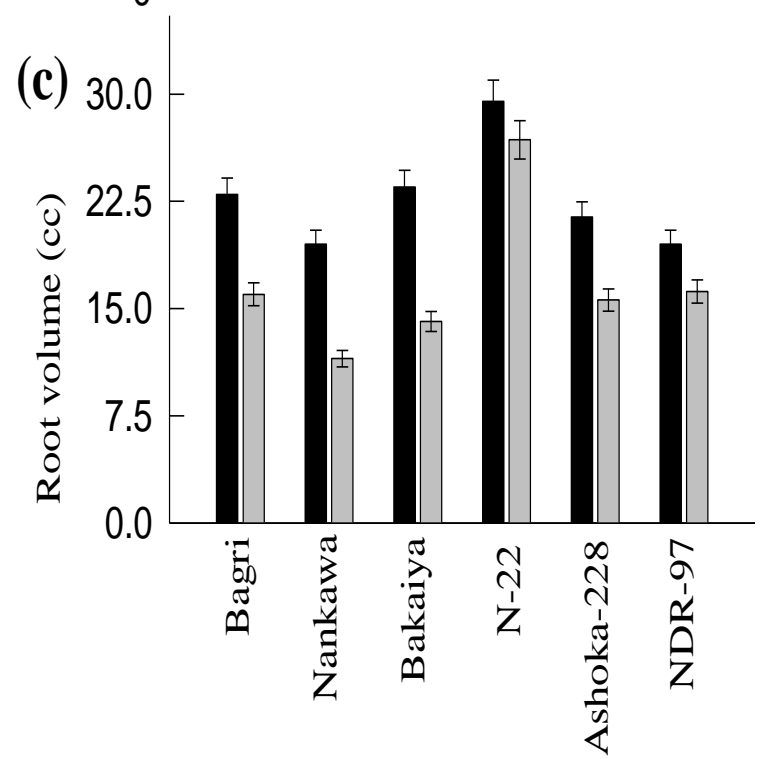

Upland rice varieties

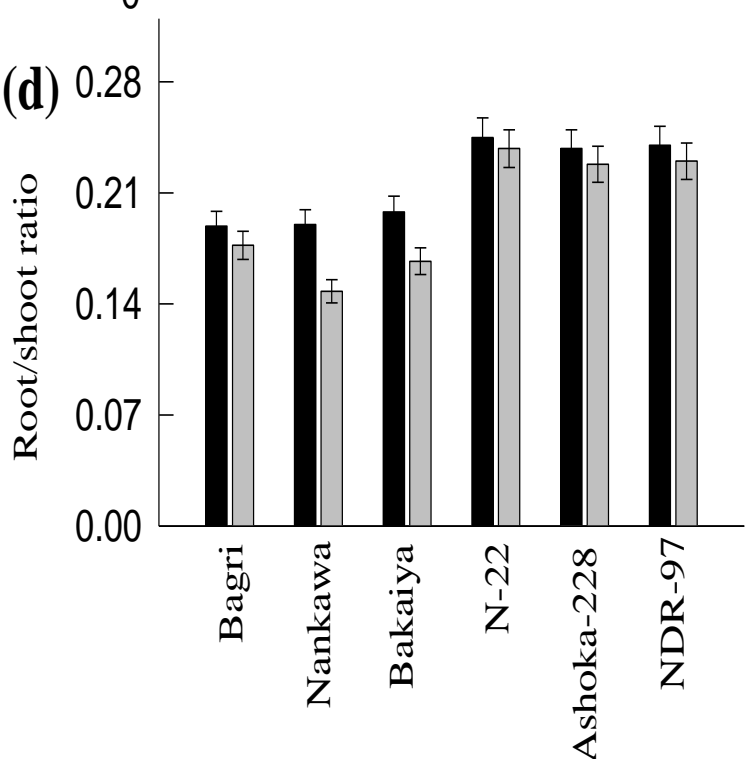

Upland rice varieties

Values in each colum are means $\pm \mathrm{SE}(\mathrm{n}=5) ; \mathrm{CT}=$ Control $(\mathrm{No}$ Drought $), \mathrm{DS}=$ Drought at $80 \mathrm{KPa} \pm 2 \mathrm{SMT}$ at $10-$ $20 \mathrm{~cm}$ depth; $\mathrm{V}=$ Variety; $\mathrm{T}=$ Treatment $\mathrm{V} \times \mathrm{T}=$ Variety $\times$ Treatment

[Least significant differences (LSD) values for plant height (V 1.46*, T 2.26*, V × T 3.20*); leaf area (V 4.72**, T $\left.8.10^{* *}, \mathrm{~V} \times \mathrm{T} 12.20^{* *}\right)$; root volume ( $\left.\mathrm{V} 0.66^{* *}, \mathrm{~T} 1.15^{* *}, \mathrm{~V} \times \mathrm{T} 1.62^{* *}\right)$; root/shoot ratio $\left(\mathrm{V} 0.01^{* *}, \mathrm{~T} 0.02^{* *}, \mathrm{~V} \times\right.$ $\mathrm{T} 0.03 * *)$ ] significant $* * \mathrm{P} \leq 0.01, * \mathrm{P} \leq 0.05$ 
Fig.2 Impact of flowering stage drought on; (a) chlorophyll content in leaves (mg/g FW); (b) starch content in culm (mg/g DW); (c) starch content in leaf sheath (mg/g DW); (d) starch content in leaf blade (mg/g DW); (e) total soluble sugar content in culm (mg/g DW); (f) total soluble sugar content in leaf sheath $(\mathrm{mg} / \mathrm{g} \mathrm{DW})$; (g) total soluble sugar content in leaf blade $(\mathrm{mg} / \mathrm{g} \mathrm{DW})$; (h) proline content in leaves $(\mathrm{mg} / \mathrm{g} \mathrm{DW})$, in six upland rice varieties
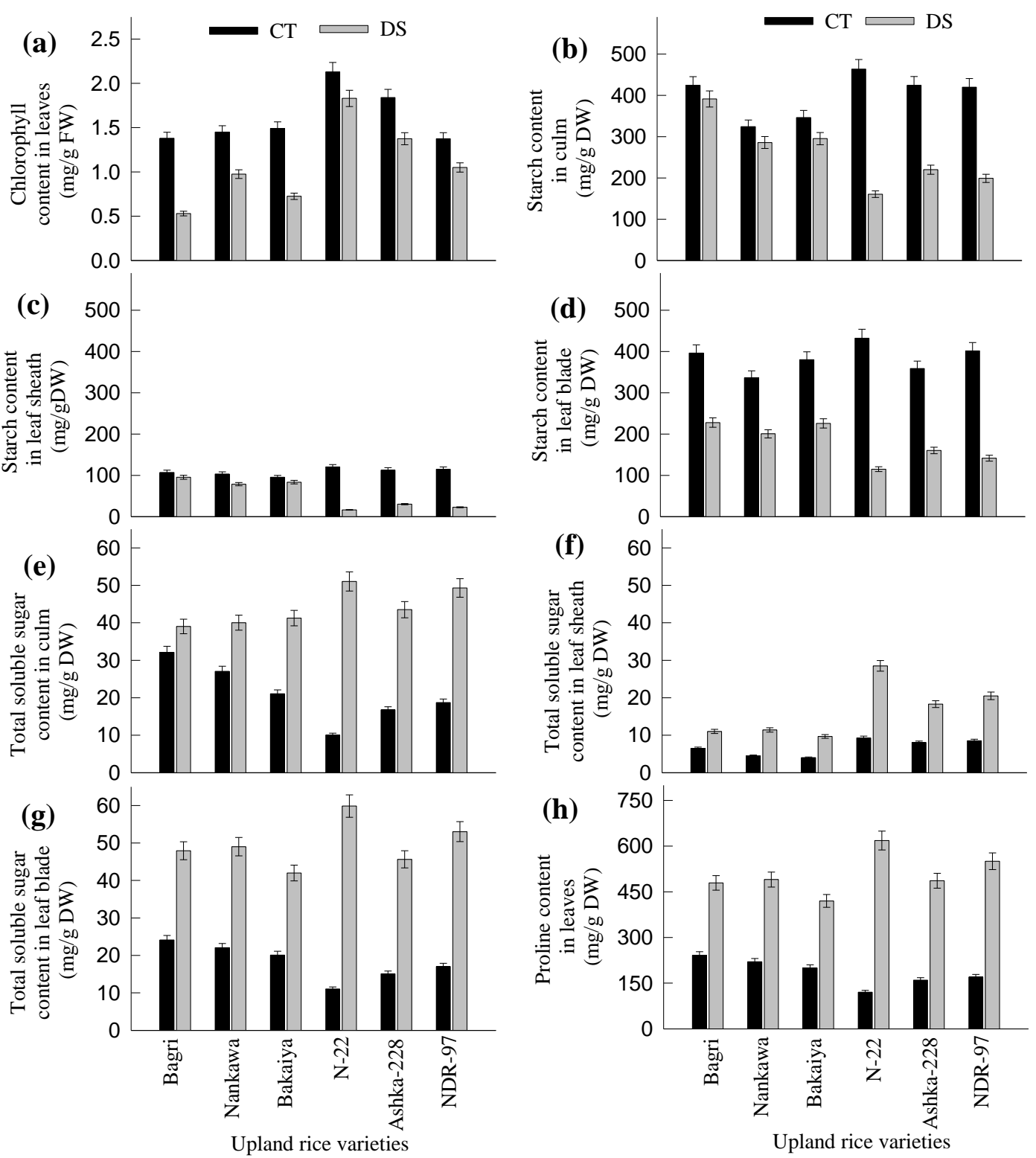

Values in each column are means $\pm \mathrm{SE}(\mathrm{n}=5) ; \mathrm{FW}=$ Fresh weight; $\mathrm{DW}=$ Dry weight; $\mathrm{CT}=$ Control (No Drought); $\mathrm{DS}=$ Drought at $80 \mathrm{KPa} \pm 2 \mathrm{SMT}$ at $10-20 \mathrm{~cm}$ depth; $\mathrm{V}=$ Variety; $\mathrm{T}=$ Treatment $\mathrm{V} \times \mathrm{T}=$ Variety $\times$ Treatment [Least significant differences (LSD) values for chlorophyll content ( $\left.\mathrm{V} 0.08^{* *}, \mathrm{~T} 0.15^{* *}, \mathrm{~V} \times \mathrm{T} 0.21 * *\right)$; starch content in culm (V 6.43***, T 13.26***, V × T 22.90***); starch content in leaf sheath (V 3.05**, T 5.29**, V × T 7.24**); starch content in leaf blade (V 11.03***, T 19.90***, $\left.\mathrm{V} \times \mathrm{T} 27.02^{* * *}\right)$; total soluble sugar content in culm (V 1.56***, T 2.68***, $\left.\mathrm{V} \times \mathrm{T} 3.90^{* * *}\right)$; total soluble sugar content in leaf sheath $\left(\mathrm{V} 1.05^{* * *}, \mathrm{~T} 2.09^{* * *}, \mathrm{~V} \times \mathrm{T}\right.$ $3.24 * * *)$; total soluble sugar content in leaf blade $\left(\mathrm{V} 1.69^{* * *}, \mathrm{~T} 2.70^{* * *}, \mathrm{~V} \times \mathrm{T} 4.90^{* * *}\right)$; proline content $(\mathrm{V}$ $12.33^{* * *}, \mathrm{~T} 24.91^{* * *}, \mathrm{~V} \times \mathrm{T} 37.02^{* * *}$ ] significant $* * * \mathrm{P} \leq 0.001, * * \mathrm{P} \leq 0.01$ 
Fig.3 Impact of flowering stage drought on; (a) biomass (g/ plant); (b) panicle/plant; (c) \% fertile spikelets/ plant; (d) grain yield g/plant in six upland rice varieties
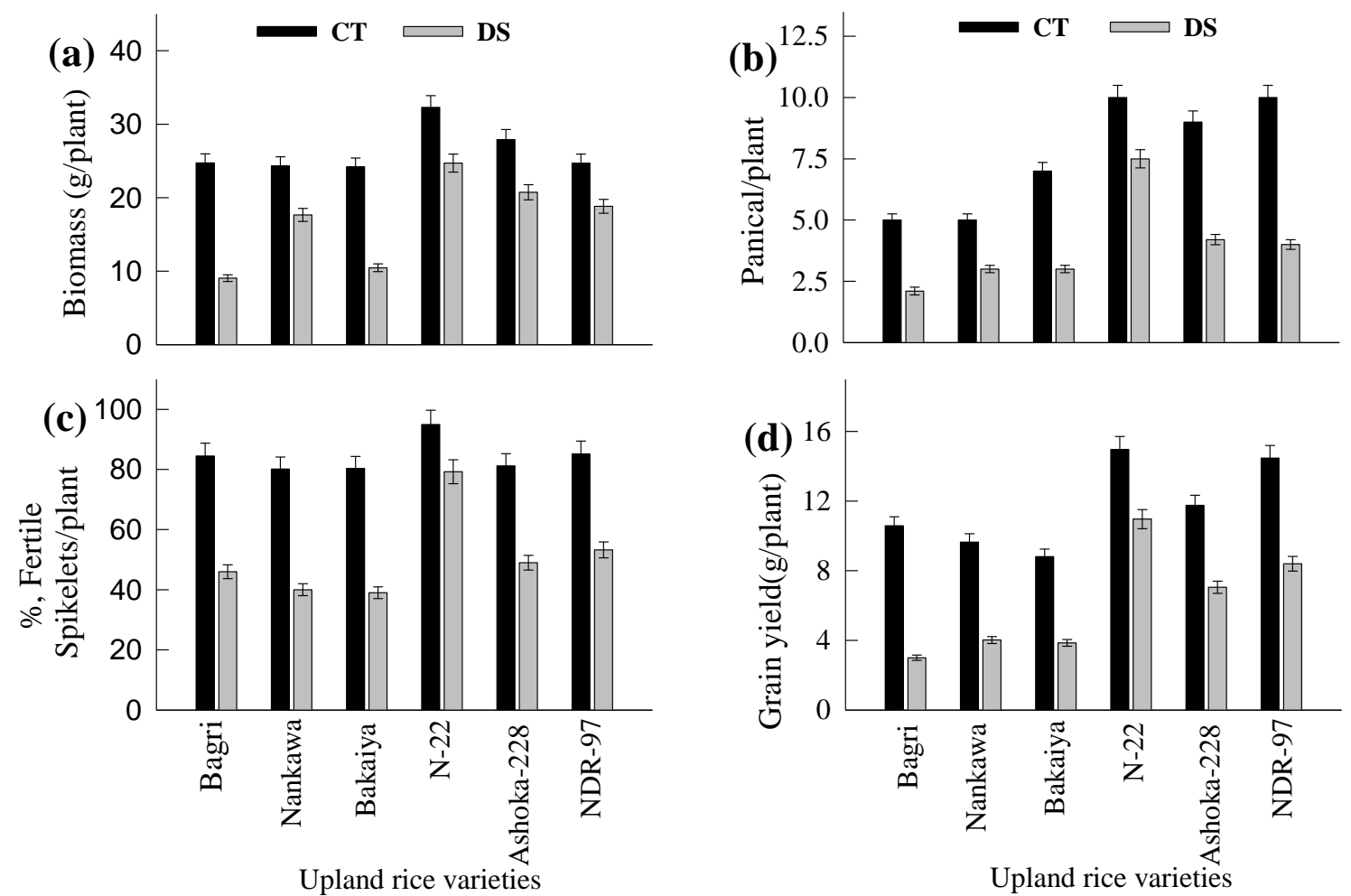

Values in each column are means $\pm \mathrm{SE}(\mathrm{n}=5)$; $\mathrm{CT}=\mathrm{Control}$ (No Drought); $\mathrm{DS}=$ Drought at $80 \mathrm{KPa} \pm 2 \mathrm{SMT}$ at 10 $-20 \mathrm{~cm}$ depth; $\mathrm{V}=$ Variety; $\mathrm{T}=$ Treatment; $\mathrm{V} \times \mathrm{T}=$ Variety $\times$ Treatment

[Least significant differences (LSD) values for Biomass (V 0.70***, T 1.21***, V $\times$ T 1.71***); panicle number $(\mathrm{V}$ $\left.0.35^{* *}, \mathrm{~T} 0.61^{* *}, \mathrm{~V} \times \mathrm{T} 0.87^{* *}\right)$; per cent fertile spikelets $\left(\mathrm{V} 1.12^{* *}, \mathrm{~T} 2.27^{* *}, \mathrm{~V} \times \mathrm{T} 3.19^{* *}\right)$; grain yield $(\mathrm{V}$ $\left.0.44^{* *}, \mathrm{~T} 0.76^{* *}, \mathrm{~V} \times \mathrm{T} 1.07^{* *}\right)$ ] significant $* * * \mathrm{P} \leq 0.001, * * \mathrm{P} \leq 0.01$

Root volume (Fig. 1c) and root/shoot ratio (Fig. 1d) have been stated to as important traits in rice conferring drought resistance. A higher root volume and root shoot ratio in varieties namely $\mathrm{N}-22$, Ashoka-288 and NDR-97 mainly determine the crops better performance under stress situations. Under drought stress higher root volume and higher root/shoot ratio indicate that these genotypes having the desired potential of deep penetrations in soil to acquire more water for its evaporative demands for higher biomass assimilation and yield. In contrast lower root volume and root/shoot ratio of varieties namely Bagri, Bakaiya and Nankawa no such characters were noticed, these varieties were poor performer for biomass and yield under drought which is in conformity with earlier reports (Feng et al., 2012, Fageria and Moreira 2011, Hsiao and Xu 2000, Mishra 2005). Decreased chlorophyll content in leaves was evident in all varieties under drought stress. It is well documented that chlorophyll is solitary central pigment of photosynthetic apparatus present in plants which absorb light and transfer light energy to the reaction centre of the photosystem. Drought stress induced decrease in chlorophyll and its components have been reported in rice (Mishra 2005, Yang et al., 2014, Pandey and Shukla 2015). Drought stress originates several changes associated to 
malformed metabolic functions, and one of those is hammering or reduced the synthesis of photosynthetic pigments. The varieties namely N-22 and Ashoka-228 maintained higher chlorophyll content and fewer distractions under drought reflecting that these are more resistant under drought. However, in Bagri and Bakaiya reductions in chlorophyll content possibly will take place due to drought stress provokes alterations in pigment biosynthetic pathways as well as in pigment deprivation, or loss of chloroplast membrane and also due to increased lipid peroxidation (Maisura et al., 2014; Huang et al., 2004).

Starch content decreased on account of drought stress in different plant parts viz. culm (Fig. 2b), leaf sheath (Fig. 2c) and leaf blade (Fig. 2d). Decrease in starch content during drought stress in different plant parts is mainly attributed due to reductions in photosynthesis a most important physiological process of carbon assimilation in plants. Starch is the major non-structural carbohydrate or reserve food material stored in different plant parts viz. culm, leaf sheath and leaf blade, when drought stress occurs this stored starch transferred and transported for providing substrate for seed set when drought stress occurs during the flowering stage. The varieties specifically $\mathrm{N}-22$ and NDR-97 having higher reductions in starch content under stress is probably due to their better capacity of drought stress resistance by sufficient accumulation and faster remobilization of starch; however, varieties i.e. Bagri and Nankawa were poor performer under drought because they lack such mechanisms (Chaturvedi et al., 1996; Huang et al., 2004; Mishra, 2005) have documented similar findings in low land and hybrid rice under drought stress.

Enhanced soluble sugar content in different plant parts viz. culm, leaf sheath and leaf blade and proline content in leaves was evident in the present investigation. The soluble sugar and proline are the osmotically active solutes found increased in plants when drought stress arises, these solutes accumulated in cytosol to lower down osmotic potential, thereby maintaining cell turgor. It is well documented that these osmotically active solutes protect plants from dehydration stress caused by drought. Increase in soluble sugars content (Mishra, 2005; Maisura et al., 2014; Usman et al., 2013) and proline content in rice has been reported (Mishra, 2005; Maisura et al., 2014; Kumar et al., 2014; Lum et al., 2014). It is reported that enhancement in soluble sugar and proline contents under stress increased several folds in drought stressed plants than the normal plants. In the present experiment higher soluble sugar and proline content on account of drought stress was evident in $\mathrm{N}-22$ and NDR-97. It reflects its superior performance under drought, in contrast lower increments in these osmotic solutes as in case of other varieties viz. Bagri, Nankawa and Bakaiya is responsible for poor performance under drought. Hence, enhanced amount of soluble sugars and proline contents can be taken as selection criteria under drought stress in rice.

Biomass per plant declined significantly under drought stress in all varieties might be due to reduced photosynthetic rate and altered morphological, physiological and biochemical processes (Centritto et al., 2009). Imposition of drought stress impaired panicle exertion as noticed in the present experiment reduction in panicle number was noticed in all varieties the reduction in panicle number is suggested as first step of stress caused detrimental impact in rice under drought (Lafitte et al., 2003). Drought stress decreased fertile spikelets $\%$ in the present experiment, this reduction is mainly due to drought stress is responsible for causing spikelets sterility probably due to 
pollen sterility and also hampered pollen fertilization (Botwright et al., 2008; Kamoshita et al., 2004; Mishra, 2005). Decreased grain yield (Fig. 3d) under drought stress in rice varieties is mainly due to reduction in grain filling period, leaf gas exchange assets, limiting the size of source and sink tissues, weakening in phloem loading and assimilate translocation (Mishra 2005, Shahryari et al., 2008). The other possible reasons of decreased seed yield in rice might be due to reduction in limiting photosynthesis due to decline in RuBISCO activity, an enzyme involved in carbon fixation in $\mathrm{C}_{3}$ crops (Zhou et al., 2007; Bota et al., 2004).

The varietal differences in grain yield as evident in the present experiment are dependent on genotypic ability to resist drought. N-22, NDR-97 and Ashoka-228 were promising genotypes might be due to its better morphological, physiological and biochemical attributes to have higher yield than others (Mishra, 2005).

From this investigation it can be concluded that drought resistance in upland rice is one of the very vital task due to its multifarious and unpredictable character. For the development of drought resistant varieties that can tolerate drought stress at flowering stage and give better yield, a systematic thoughtful understanding of the different physiological, biochemical traits that govern the yield and yield traits in upland rice is must and prerequisite for breeding purposes to ensure food security.

\section{Acknowledgements}

Authors are thankful to Dr. V. N. Singh rice breeder crop research station, Masodha, for providing upland rice seeds. We express our thanks to the director and head centre of advance studies in plant physiology and department of crop physiology for providing all necessary facilities to complete the research work.

\section{Abbreviations}

CT-control (no drought); DS-drought stress; LSD-least significant differences; CC-cubic centi liter; KPa-kilo pascal; SMT-soil moisture tension; $\mathrm{V}=$ Variety; $\mathrm{T}=$ Treatment; $\mathrm{V} \times \mathrm{T}=$ Variety $\times$ Treatment

\section{References}

Arnon, D.I. 1949. Copper enzymes in isolated chloroplasts, Poly-phenol oxidase in Beta vulgaris. Plant Physiology. 24: 115.

Bates, L.S., Waidren, R.P. and Teare, I.D. 1973. Rapid determination of free proline for water stress studies. Plant Soil. 39: 205-207.

Bota, J., Medrano, H. and Flexas, J. 2004. Is photosynthesis limited by decreased Rubisco activity and RuBP content under progressive water stress? New Phytologist. 162(3): 671-681.

Botwright Acuña, T.L., Latte, H.R. and Wade, L.J. 2008. Genotype and environment interactions for grain yield of upland rice backcross lines in diverse hydrological environments. Field Crop Research. 108(2): 117-125.

Centritto, M., Lauteri, M., Monteverdi, M. C. and Serraj, R. 2009. Leaf gas exchange, carbon isotope discrimination and grain yield in contrasting rice genotypes subjected to water deficits during the reproductive stage. Journal of Experimental Botany. 60(8): 23252339.

Chaturvedi, G.S. and Ingram, K.T. 1988. Assimilate translocation of lowland rice in response to water deficit and shade. Philippine Journal of Crop Science. 13 (1):55-59. 
Chaturvedi, G.S., Ram, P.C., Singh, A.K., Ingram, K.T., Singh, B.B., Singh, P.K., and Singh, V. P. 1996. (Eds.). In: Physiology of Stress Tolerance in Rice, IRRI Publication: 103-122.

Dubois, M., Gilles, K.A., Hamilton, J.K., Rebers, P.A. and Smith, F. 1956. Colorimetric method for determination of sugar and related substances. Annals of Chemistry. 28: 350-356.

Fageria, N.K. and Moreira, A. 2011. The role of mineral nutrition on root crop growth of crop plants. Advances in Agronomy. 110: 251-331.

Feng, F.J., Xu, X.Y., Du, X.B., Tong, H.H., Luo, L.J. and Mei, H.W. 2012. Assessment of drought resistance among wild rice accessions using a protocol based on single-tiller propagation and PVC-tube cultivation. Australian Journal of Crop Science. 6: 1205-1211.

Fukai, S., and Cooper, M. 1995. Development of drought-resistant cultivars using physico-morphological traits in rice. Field Crop Research. 40: 67-86.

Hasanuzzaman, M., Nahar, K., Gill, S.S., Gill, R. and Fujita, M. 2014. Drought stress responses in plants, oxidative stress and antioxidant defense. In: Gill S.S, and Tuteja, N. (Eds.). Climate Change and Plant Abiotic Stress Tolerance. Blackwell, Germany: Wiley. 209-249.

Hiscox, J.D. and Israelstam, G.F. 1979. A method for the extraction of chlorophyll from leaf tissue without maceration. Canadian Journal of Botany. 57: 13321334.

Hsiao, T.C. and Xu, L.K., 2000. Sensitivity of growth of roots verses leaves to water stress: Biophysical analysis and relation to water transport. Journal of Experimental Botany. 51: 1595-1616.

Huang, S.M., Zou, Y.B. and LI, S.Q. 2004. Vascular bundles features and physiology character of hybrid rice
(Liangyoupeijiu). Journal of Human Agricultural University. 30(1): 1-3.

Jaleel, C.A., Manivannan, P., Wahid, A., Farooq, M., Al-Juburi, H.J., Somasundaram, R. and Panneerselvam, R. 2009. Drought stress in plants: A review on morphological characteristics and pigments composition. International Journal of Agriculture and Biology. 11: 100-105.

Kadioglu, A. and Terzi, R. 2007. A dehydration avoidance mechanism: Leaf rolling. Botanical Review. 73(4): 290-302.

Kamoshita, A., Rofriguez, R., Yamauchi, A. and Wade, L.J. 2004. Genotypic variation in response of rainfed lowland rice to prolonged drought and rewatering. Plant Production Science. 7(4): 406-420.

Kumar, S., Dwivedi, S.K., Singh, S.S., Bhatt, B.P., Mehta, P., Elanchezhian, R., Singh, V. P. and Singh, O.N. 2014. Morphophysiological traits associated with reproductive stage drought tolerance of rice (Oryza sativa L.) genotypes under rain-fed condition of eastern Indo-Gangetic Plain. Indian Journal of Plant Physiology. 19(2): 8793.

Lafitte, R., Blum, A. and Altin, G. 2003. Using secondary traits to help identify drought tolerant genotypes. In: Breeding rice for drought prone environments, IRRI, Publication. pp. 37-48.

Lum, M.S., Hanafi, M.M., Rafii, Y.M. and Akmar, A.S.N. 2014. Effect of drought stress on growth, proline and antioxidant enzyme activities of upland rice. Journal of Animal and Plant Science. 24(5): 1487-1493.

Maisura, Chozin, M.A., Lubis, I., Junaedinand, A. and Ehara, H. 2014. Some physiological character responses of rice under drought conditions in a 
paddy system. Journal of International Society of Southeast Asian Agricultural Science. 20(1): 104-114.

Mishra, B.K. 2005. Histochemical studies on accumulation and remobilization of starch at flowering stage in upland rices. M.Sc. Thesis, Narendra Deva University of Agriculture of Agriculture and Technology, Narendra Nagar, Kumarganj, Faizabad, U.P., India.

Pandey, V. and Shukla, A. 2015. Acclimation and tolerance studies in rice under drought stress. Rice Science. 22(4): 147-161.

Rao, M.J.B.K., Sampath, S. and Murthy, K.S. 1971. Breeding varieties for special situations. Indian Farming. 21(7): 45-52.

Ray, D.K., Gerber, J.S., MacDonald, G.K., and West, P.C. 2015. Climate variation explains a third of global crop yield variability. Nature Communication 6: $59-89$.

Serraj, R., McNally, K.L., Slamet-Loedin, I., Kohli, A., Haefele, S.M., Atlin, G., and Kumar, A. 2011. Drought resistance improvement in rice: An integrated genetic and resource management strategy. Plant Production Science. 14(1): 1-14.

Shahryari, R., Gurbanov, E., Gadimov. A. and Hassanpanah, D. 2008. Tolerance of 42 bread wheat genotypes to drought stress after anthesis. Pakistan Journal of Biological Science. 11(10): 1330-1335.
Shao, H.B., Chu, L. Y., Shao, M.A., Jaleel, C.A., and Mi, H.M. 2008. Higher plant antioxidants and redox signalling under environmental stresses. Comp Rend Biology. 331: 433-441.

Sikuku, P.A., Onyango, J.C. and Netondo, G.W. 2012. Physiological and biochemical responses of five nerica rice varieties (Oryza sativa L.) to water deficit at vegetative and reproductive stage. Agricultural Biology Journal of North America. 3(3): 93-104.

Usman, M., Raheem, Z.F., Ahsan, T., Iqbal, A., Sarfaraz, Z.N. and Haq, Z. 2013. Morphological, physiological and biochemical attributes as indicators for drought tolerance in rice (Oryza sativa L.). European Journal of Biological Science. 5(1): 23-28.

Yang, P.M., Huang, Q.C., Qin, G.Y., Zhao, S.P., and Zhou, J.G. 2014. Different drought-stress responses in photosynthesis and reactive oxygen metabolism between autotetraploid and diploid rice. Photosynthetica. 52(2): 193-202.

Zhou, Y., Lam, H.M. and Zhang, J. 2007. Inhibition of photosynthesis and energy dissipation induced by water and high light stresses in rice. Journal of Experimental Botany. 58(5): 12071217.

Zhu, J.K. 2002. Salt and drought stress signal transduction in plants. Annual Review of Plant Biology. 53: 247-273.

\section{How to cite this article:}

Mishra, B.K. and Chaturvedi, G.S. 2018. Flowering Stage Drought Stress Resistance in Upland Rice in Relation to Physiological, Biochemical Traits and Yield. Int.J.Curr.Microbiol.App.Sci. 7(02): 71-82. doi: https://doi.org/10.20546/ijcmas.2018.702.010 